\title{
Role of DNA Barcoding in Plant Biodiversity Conservation
}

\author{
Qasim Farooq, Muhammad Shakir", Farial Ejaz, Tooba Zafar, Kinat Durrani, Azmat Ullah
}

Department of Botany, University of Agriculture, Faisalabad, University Main Rd, Faisalabad, Punjab 38000, Pakistan

DOI: $\underline{10.36348 / \mathrm{sijb} .2020 . \mathrm{v} 03 \mathrm{i} 03.002}$

| Received: 03.03.2020 | Accepted: 10.03.2020 | Published: 18.03 .2020

*Corresponding author: Muhammad Shakir

\section{Abstract}

To prove the importance of DNA barcode one of the major point is that the genetic data is an important factor to improve the biodiversity conservation strategies and in fact at the different level of analysis in conservation biology many molecular tools. The aim of this review article is to access the role of DNA barcoding in biodiversity conservation in For the fine scale management of plant species, coral reefs, identification of cryptic and invasive species and regional management of fisheries in the field conservation biology molecular tools offer a great help. DNA barcoding had contribution in the conservation policy in such a way is that it came forward with the success of conservation action and other one is that it provide useful information about phylogenetic diversity and also about evolutionary history.

Keywords: Conservation biology, DNA barcoding, Phylogenetic diversity, Biodiversity.

Copyright @ 2020: This is an open-access article distributed under the terms of the Creative Commons Attribution license which permits unrestricted use, distribution, and reproduction in any medium for non-commercial use (NonCommercial, or CC-BY-NC) provided the original author and source are credited.

\section{INTRODUCTION}

DNA barcoding has ability to identify the species very rapidly and cheaply, this efficiency of the barcoding is the central argument in favor to use the DNA barcoding [1]. Within the decade of research explained that DNA barcode of $0.1 \%$ of all the described animal species have been collected. It was estimated that morphological analysis takes place at the cost of $\$ 100$ per specimen with several months of field work as compared to the sequencing of species that require only the cost of $\$ 2-5$ per species under the time of 90 minutes These suppositions we can use the purely genetic analysis but the DNA barcoding papers are more popular that they contain traditional taxonomic research methods, such as in the identification of differences in the food habits and also the larval appearance of cryptic species of skipper butterflies [2].

This approach proposes that taxonomical research is going to become integrative, by combining the analysis of traditional morphologies with the development in innovative technologies, although all of this need resource investment. However another argument emerges that when first investment was made for the development of reliable database, barcoding was proved to quickly identify the specimens that were newly collected. Furthermore research is important to test the whether the barcoding is effective or not but now as the technologies and genetic sequencing techniques developed and cheaper it make research much more convenient and less time consuming [3].

The basic research priority is the quick assessment of biodiversity that give the extinction assay of ongoing species. The most important investment of barcoding to conservation of biodiversity is that it facilitates the biodiversity assessment in a very cheap and quick way at that time when there are inadequate financial resources. This is an important point because most of the biodiversity is present in the under developed countries where resources for biodiversity are very limited. There is successful notable conservation by using the DNA barcoding as in the case of South Asian mammals, the barcoding was used for the identification of endemism and also the structure of intra- specific population [4].

\section{Biodiversity Assessments}

The impotent role of barcoding is the identification of species, where the morphology has its own limitations because the morphological keys are limited only to the specific gender and also at a particular stage of life [5]. This point is especially true in case of those arthropods for which the recent taxonomic studies were not sufficie. Barcoding was involved to classify those species that have a diversity in their life style including aphids [6]. 


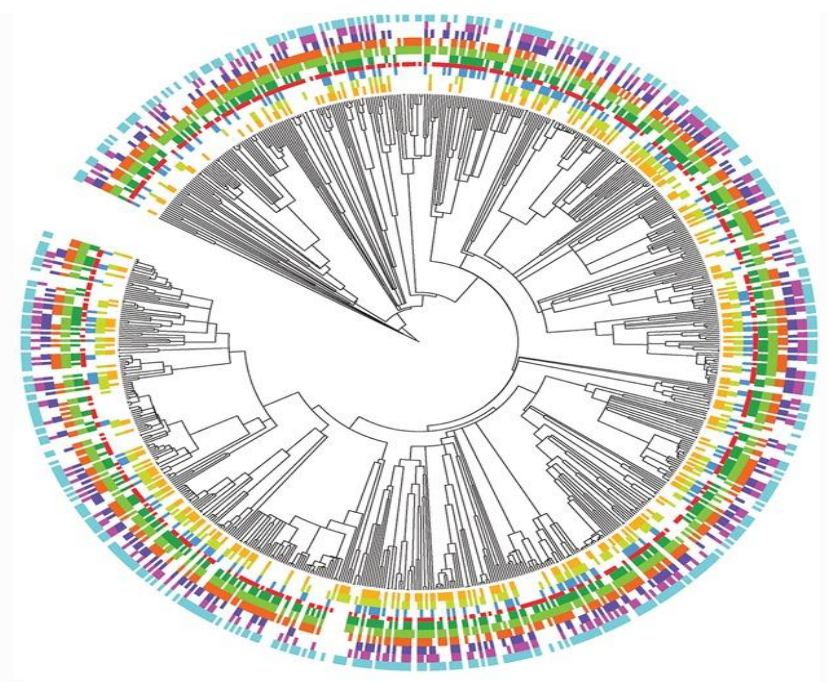

Fig-1: DNA barcodes to map phylogenetic diversity for habitat conservation

DNA barcoding was also helpful in the identification of new species. It is also known that the vide variety of species are not discovered yet, so that for the discovery of new species a cheaper, objective and a standardized method like DNA barcoding received much more importance in this era [7]. However the use of DNA barcoding for specie identification is the most controversial use of barcodes. Facts describe that the DNA sequencing is the simplest way to identify and explain new specie. It was also said that to precisely describe a specie barcoding can be used in combination with the traditional taxonomic methods [8].

\section{Role in Discovery of New Species}

In fact, solely the barcodes only can be utilized to propose a hypothesis about new specie instead of discovering new specie [9]. Therefore, these results explained that there should be a flexible threshold that describe those species that are already identified and accepted, these results also highlight this fact that the barcoding on its own as a technique have certain limitations [10]. On the basis flexibility of threshold, DNA barcoding results can be manipulated for the different political purpose [11]. However the analysis in which we cannot perceive the obvious differences, a question was raised that whether the conservation that was done on the basis of only mtDNA was able to get public support or not [12].

The attribution of taxonomic rank that was based on the genetic analysis is not as clear as it should be, there were also facts supporting that genetic distance is an important tool to determine the boundaries of species because genetic divergence is present in higher concentration in the species that are closely related as compared to the individuals of same species [13].

The potential of DNA barcoding for the identification of intra and inter specific variability was appreciated in different studies. Such type of studies illustrated that for specific taxonomic groups it is possible to set-up the strong threshold for the identification of intra and inter-specific variability [5]. in spite of the difficulty to develop a stranded threshold, where variability threshold can be determined, the complexity of species can be understodd more sufficiently and taxonomic groups can be easily studied [14].

\section{DNA barcoding for Assessments of Phylogenetic Diversity}

To design and prioritize the conservation area, we should rely on the indicators of species diversity, value and richness [15]. One of these indicators is the phylogenetic diversity that is involved in the measurement of taxonomic divergence in different species. It is calculated as "the sum of the lengths of all the branches that are members of the corresponding minimum spanning path" 4). The catalogue of phylogenetic diversity provide information about the strategies to conserve the species by ignoring less important species and through the use of evolutionary phylogenies to improve the prediction about the pattern of biodiversity [16]. Even it was stated that the most important contribution of DNA barcoding in the conservation of species is its role in betterment and speeding up the assessments of phylogenetic diversity [17]. 


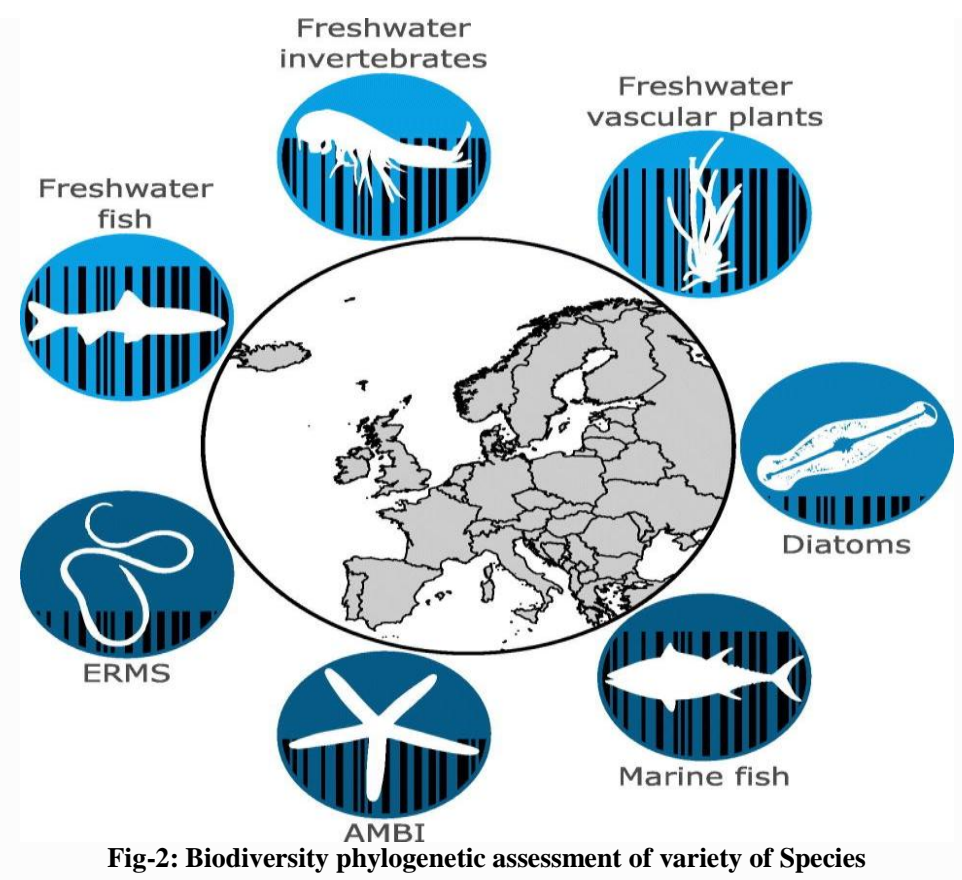

The important role of phylogenetic diversity in the plan to conserve the species suggests that the incorporation of PD analysis tools and the web based barcoding database results in improved phylogenetic calculations [18]. Such type of approach includes the data collection from the combination of mtDNA barcode based phylogenetic data and the data from broader phylogenetic database [19]. For the accurate prediction of global biodiversity pattern the one of the greatest challenge for the PD analysis is that the phylogenetic studies always need many more taxa which create different problems [20].

\section{Emerging perspectives in Biodiversity conservation}

Results describe that planning that was introduced by the DNA barcoding technique for the conservation of species is quite easy to replicate with negligible field work and cost- efficient [21]. This point was explained as we can get more than 1000 sequences of 100 base pairs through the automated sequencers every day, even for the non- genetic can researchers can easily get the genetic sequences through companies that provide their service at very affordable price. Initial research work shows that through barcoding techniques we can replicate a smaller sequence at very faster rate to improve the identification of species for those mini barcodes in which DNA have degraded in the archival specimens that contain the biological material [22].

An experimental study of 691 species consist on about 1,566 specimens shows that for the classification of species we can utilize as small as 100 base pair or as long as 250 base pairs with maximum rates of success. Mini-barcodes were proved helpful when we need a rough picture of species diversity instead of explained diversity analysis data [23].
The continuous success of the different techniques used in DNA barcoding in animals have made researchers more optimistic to develop application of barcoding in the other kingdom, especially the plant species that are harder to classify with the genetic tools [24].

For the plants DNA barcoding has been problematic because of the fact that those genes that are used as phylogenetic marker in the land plants are involved in very limited variations that are not enough to determine the specie limit or not enough to differentiate the species [25]. To overcome this problem some studies suggest techniques that are based on a single chloroplast region or a combination of different regions [25].

On the whole all the debate summarized to a fact that different genetic markers are applied to plant and get different success rates, for example to classify the angiosperms trnH-psbA, rp136-rpf8, and $t r n L-$ $F$ have been used and results were quite successful, similarly for the identification of series of many medicinal plants ITS2 have been used as a successful phylogenetic marker. ITS region have also been involve in successful classification of angiosperms and for ferns $r b c L$ and $t r n L-F$ was used as two locus DNA barcode [26]. Plastid markers $r b c L$, matK, and $t r n H-p s b A$ was used recently with the success rate of 87.1-92.7\% in DNA barcoding. Recent research results explained the application of DNA barcoding on plants using combination of genetic markers [7]. As the advancement takes place in the barcoding techniques it also introduce us useful inputs to made a standardized barcode for the plants and also for the potentially other complex taxa [27]. 
The non-experts of barcoding can also use the barcoding for different purpose other than the taxonomy studies with the help of technology (used to collect ant interpret the barcoding data) that become more easily accessible and affordable [28]. DNA samples can also be used for the testing of drug authentication in the field of forensics [29]. While in the biosecurity, DNA baroding was helpful in finding exotic species with a very quick and reliable method, for example North American bullfrog (Rana catesbeiana) was discovered in France by utilizing the small mitochondrial fragments that were found in the water of pound. In the field of biomedical, improvements in technologies that leads to the next generation DNA sequencing have better ability to speed up the research that leads to the comprehensive analysis of DNA barcodes, interactomes, genomes and transcriptome [26].

The traditional species concepts are also redefined by the DNA barcoding studies. Metagenetic studies have also been integrated with barcoding [11]. Operational taxonomic units were focused by these techniques instead of traditional concepts of morphological species. Such approaches are helpful in the determination of ecological value eukaryotic microbiota, in which there are different challenges in correct identification; these challenges include the unclear morphological characters, diversity and minute size [30].

For the biodiversity assessments the OTUs based metagenetic studies are being used as an important strategy. Such researches explained the role of DNA barcoding in enhancing enhancing biodiversity assessment, and therefore on conservation efforts [31]. As distance based method face many challenges in the identification of species, another better method have been proposed that was based on character based barcodes [32].

The positive point character-based DNA barcode is that it provide a set of molecular data that can easily be incorporated into the classical taxonomic data in such a way that the discovery of new species can be made in an analytical framework that contain data from multiple sources so that the discrimination between two species become more easy and convenient [13]. This method is more promising in those cases in which there is significant overlap between the intraspecific and interspecific divergences in those primers that were being used in the classification [33].

\section{CONCLUSION}

Advancements have been made to provide useful and appropriate information about the plants species and their genome. DNA barcoding in conjugation with other branches of sciences such as ecology and taxonomy needed for discovery of specices. It will help to collect data about particular species and then analyze using molecular tools for conservation of biodiversity. Various databases will be use effectively consideration for proper storage of data about species for conservation of biodiversity.

\section{REFERENCES}

1. Frézal, L., \& Leblois, R. (2008). Four years of DNA barcoding: current advances and prospects. Infection, Genetics and Evolution, 8(5), 727-736.

2. Hebert, P. D., DeWaard, J. R., \& Landry, J. F. (2010). DNA barcodes for $1 / 1000$ of the animal kingdom. Biology letters, 6(3), 359-362.

3. Shendure, J., \& Ji, H. (2008). Next-generation DNA sequencing. Nature biotechnology, 26(10), 1135.

4. Francis, C. M., Borisenko, A. V., Ivanova, N. V., Eger, J. L., Lim, B. K., Guillén-Servent, A., ... \& Hebert, P. D. (2010). The role of DNA barcodes in understanding and conservation of mammal diversity in Southeast Asia. PloS one, 5(9):e12575.

5. Group, C. P. W., Hollingsworth, P. M., Forrest, L. L., Spouge, J. L., Hajibabaei, M., Ratnasingham, S., ... \& Fazekas, A. J. (2009). A DNA barcode for land plants. Proceedings of the National Academy of Sciences, 106(31), 12794-12797.

6. Foottit, R. G., Maw, H. E. L., Havill, N. P., Ahern, R. G., \& Montgomery, M. E. (2009). DNA barcodes to identify species and explore diversity in the Adelgidae (Insecta: Hemiptera: Aphidoidea). Molecular Ecology Resources, 9, 188-195.

7. Casiraghi, M., Labra, M., Ferri, E., Galimberti, A., \& De Mattia, F. (2010). DNA barcoding: a sixquestion tour to improve users' awareness about the method. Briefings in bioinformatics, 11(4), 440-453.

8. Hausmann, A., Miller, S. E., Holloway, J. D., Dewaard, J. R., Pollock, D., Prosser, S. W., \& Hebert, P. D. (2016). Calibrating the taxonomy of a megadiverse insect family: 3000 DNA barcodes from geometrid type specimens (Lepidoptera, Geometridae). Genome, 59(9), 671-684.

9. Goldstein, P. Z., \& DeSalle, R. (2011). Integrating DNA barcode data and taxonomic practice: determination, discovery, and description. Bioessays, 33(2), 135-147.

10. Andersen, K., Bird, K. L., Rasmussen, M., Haile, J., Breuning-Madsen, H. E. N. R. I. K., Kjaer, K. H., ... \& Willerslev, E. (2012). Meta-barcoding of 'dirt'DNA from soil reflects vertebrate biodiversity. Molecular Ecology,21(8), 19661979.

11. Zhang, J., Kapli, P., Pavlidis, P., \& Stamatakis, A. (2013). A general species delimitation method with applications to phylogenetic placements. Bioinformatics, 29(22), 2869-2876.

12. Witt, J. D., Threloff, D. L., \& Hebert, P. D. (2006). DNA barcoding reveals extraordinary cryptic diversity in an amphipod genus: 
implications for desert spring conservation. Molecular ecology, 15(10), 30733082.

13. Garraffoni, A. R. S., \& Freitas, A. V. L. (2017). Photos belong in the taxonomic Code. Science, 355(6327), 805-805.

14. Lakra, W. S., Verma, M. S., Goswami, M., Lal, K. K., Mohindra, V., Punia, P., ... \& Hebert, P. (2011). DNA barcoding Indian marine fishes. Molecular Ecology Resources, 11(1), 6071.

15. Creedy, T. J., Norman, H., Tang, C. Q., Qing Chin, K., Andujar, C., Arribas, P., ... \& Vogler, A. P. (2020). A validated workflow for rapid taxonomic assignment and monitoring of a national fauna of bees (Apiformes) using high throughput DNA barcoding. Molecular ecology resources, 20(1), 40-53.

16. de Vere, N., Rich, T. C., Ford, C. R., Trinder, S. A., Long, C., Moore, C. W., ... \& Tatarinova, T. (2012). DNA barcoding the native flowering plants and conifers of Wales. PloS one, 7(6): 37945 .

17. Mitchell, A. (2008). DNA barcoding demystified. Australian Journal of Entomology, 47(3), 169-173.

18. Iyengar, A. (2014). Forensic DNA analysis for animal protection and biodiversity conservation: a review. Journal for Nature Conservation, 22(3), 195-205.

19. Andújar, C., Arribas, P., Gray, C., Bruce, C., Woodward, G., Yu, D. W., \& Vogler, A. P. (2018). Metabarcoding of freshwater invertebrates to detect the effects of a pesticide spill. Molecular Ecology, 27(1), 146-166.

20. Baker, A., \& Faith, D. (2006). Phylogenetic diversity (PD) and biodiversity conservation: some bioinformatics challenges. Evolutionary Bioinformatics Online, 2, 70-77.

21. Goldstein, P. Z., \& DeSalle, R. (2019). Review and interpretation of trends in DNA barcoding. Frontiers in Ecology and Evolution, 7, 302.

22. Kress, W. J., \& Erickson, D. L. (2008). DNA barcodes: genes, genomics, and bioinformatics. Proceedings of the National Academy of Sciences, 105(8), 2761-2762.

23. Valentini, A., Pompanon, F., \& Taberlet, P. (2009). DNA barcoding for ecologists. Trends in ecology \& evolution, 24(2), 110-117.
24. Costion, C., Ford, A., Cross, H., Crayn, D., Harrington, M., \& Lowe, A. (2011). Plant DNA barcodes can accurately estimate species richness in poorly known floras. PloS one, 6(11):e26841.

25. Hollingsworth, P. M. (2011). Refining the DNA barcode for land plants. Proceedings of the National Academy of Sciences, 108(49), 1945119452.

26. Ficetola, G. F., Miaud, C., Pompanon, F., \& Taberlet, P. (2008). Species detection using environmental DNA from water samples. Biology letters, 4(4), 423-425.

27. Li, R., \& Dao, Z. (2011). Identification of Meconopsis species by a DNA barcode sequence: the nuclear internal transcribed spacer (ITS) region of ribosomal deoxyribonucleic acid (DNA). African Journal of Biotechnology, 10(70), 15805-15807.

28. Arif, I. A., Bakir, M. A., Khan, H. A., Al Farhan, A. H., Al Homaidan, A. A., Bahkali, A. H., ... \& Shobrak, M. (2010). A brief review of molecular techniques to assess plant diversity. International Journal of Molecular Sciences, 11(5), 2079-2096.

29. Bell, K. L., Burgess, K. S., Okamoto, K. C., Aranda, R., \& Brosi, B. J. (2016). Review and future prospects for DNA barcoding methods in forensic palynology. Forensic Science International: Genetics, 21, 110-116.

30. Hollingsworth, P. M., Graham, S. W., \& Little, D. P. (2011). Choosing and using a plant DNA barcode. PloS one, 6(5):e19254.

31. Porazinska, D. L., Giblin-Davis, R. M., Sung, W. A. Y., \& Thomas, W. K. (2010). Linking operational clustered taxonomic units (OCTUs) from parallel ultra sequencing (PUS) to nematode species. Zootaxa, 2427(1), 55-63.

32. Ceriaco, L. M., Gutiérrez, E. E., Dubois, A., \& Carr, M. (2016). Photography-based taxonomy is inadequate, unnecessary, and potentially harmful for biological sciences. Zootaxa, 4196(3), 435445.

33. Yassin, A., Markow, T. A., Narechania, A., O’Grady, P. M., \& DeSalle, R. (2010). The genus Drosophila as a model for testing tree-and character-based methods of species identification using DNA barcoding. Molecular Phylogenetics and Evolution, 57(2), 509-517. 